\title{
Development of an integrated passive cooling façade technology for office buildings in hot arid regions
}

\author{
A. Abu Khadra \& N. Chalfoun \\ College of Architecture, Planning and Landscape Architecture, \\ The University of Arizona, USA
}

\begin{abstract}
Building envelopes play a major role in improving the overall energy efficiency as well as in providing a healthy indoor air quality for occupants in office buildings.

The notion of this research is to develop an integrated façade technology that interacts and adapts with the changing climatic conditions, in hot arid regions, in order to improve occupants' thermal comfort in mixed mode office buildings through the use of natural ventilation and evaporative cooling techniques, thereby reducing mechanical cooling energy loads.

In this research, façade design decisions were based on two main computer simulation results; thermal comfort levels and the reduction in energy consumption. The authors propose a double skin façade system that consists of an external skin which works on multiple operating modes. This skin integrates passive cooling strategies with the building envelope depending on the data collected by external and internal sensors. My previous investigations showed that shading, natural ventilation and evaporative cooling are the most effective passive cooling strategies for hot and arid regions

In conclusion, this research will contribute in reducing energy consumption in commercial buildings, and help provide a productive work environment.

Keywords: passive cooling, arid regions, evaporative cooling, double skin facades, dynamic facades, thermal comfort, illuminance, glare, CFD simulation.
\end{abstract}




\section{Introduction}

Recent research, conducted by the United States Environmental Protection Agency (EPA), shows that $49 \%$ of the total energy consumption in the US goes to the building sector. Commercial buildings accounted for almost $51 \%$ of that total. $72 \%$ of the total electricity generated by US power plants goes to supply the building sector. Cooling, of commercial buildings consumes $38 \%$ of the total electricity provided for this sector [1].

Typically, highly glazed facades lead to increasing the heat transfer between indoor spaces and outdoor environment. To overcome this problem and to maintain occupants' thermal comfort, designers have had to depend on mechanical systems as they are the easiest and most available option. This problem is more apparent in hot regions where unshaded glazed facades can cause overheating issues which require mechanical cooling. In hot arid regions, each $1 \%$ increase in the $\mathrm{WWR} \simeq 0.6 \%$ increase in annual energy consumption per sq. ft of south-facing office spaces [2]. Mechanical cooling causes a tremendous increase in the total energy consumption for buildings, and therefore there was a need to think of other efficient means of cooling that can tremendously reduce cooling energy loads while maintaining the appropriate thermal comfort levels for the occupants.

\subsection{Theory}

Nature can offer great examples of adaptation, such as the adaptation of beings with the environmental and climatic conditions and the perfect thermoregulation process that can maintain these beings in comfort. Such examples have inspired architects and designers to apply these concepts to their designs.

The human body can perfectly respond and adapt to internal and external thermal changes through its different parts to maintain comfort levels. When the body temperature (Core, skin or both) is elevated, the hypothalamus is stimulated to increase blood flow to the skin (vasodilation) and produce sweat to eliminate excess body heat. These signals are sent through the sympathetic nervous system to skin arterioles and eccrine sweat glands [3].

The human skin is the main separator between the body and external environments, and is also the medium between the core of the human body and the external conditions. Therefore, it is the part through which the adaptation and the thermal regulation occurs. When looking at buildings, we find that the building envelope plays a major role as a thermal barrier that controls heat transfer between the indoor and outdoor spaces along with potentially providing healthy indoor environment for occupants.

In this project, the authors are proposing an analogy between the thermoregulation processes of the human body and buildings, to help optimize buildings thermal performance of buildings.

The building skin should be as dynamic, intelligent and efficient as the human skin in terms of function, performance and integration with the building systems and morphology (fig. 1), in order to optimize the thermal regulation process and increase the thermal comfort levels in interior spaces. 


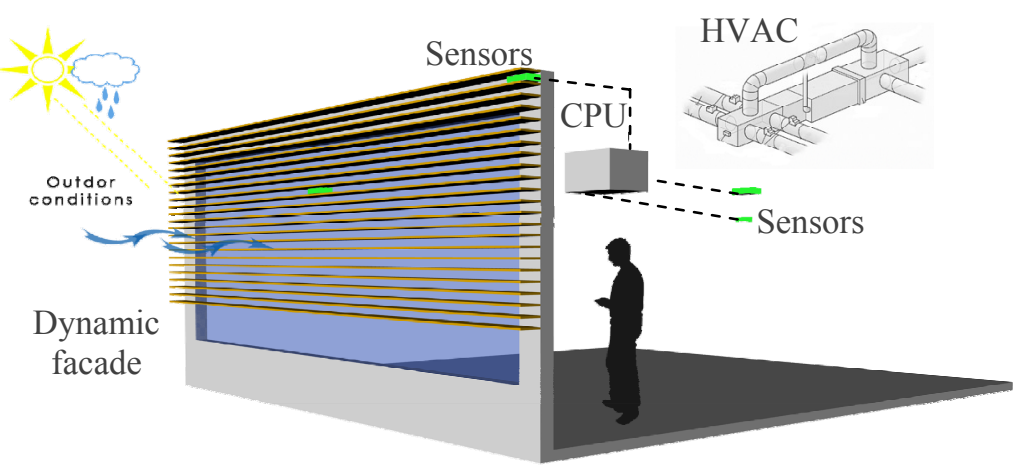

Figure 1: Optimization of a building performance requires integration of building systems and morphology.

\subsection{Rationale}

As mentioned previously; cooling loads take the biggest share of buildings energy consumption in hot arid regions. A thorough climatic analysis, using Climate Consultant 5.4 software, was conducted on Tucson, Arizona $\left(32.2^{\circ} \mathrm{N}\right.$, $110.9^{\circ} \mathrm{W}$ ) as an example of hot arid regions to determine efficient passive cooling methods that can be used to optimize the thermal and energy performance of office building.

Dry and wet bulb temperatures, relative humidity and wind speed, which are the main indices to determine thermal comfort, were studied to identify the most efficient ways of cooling in Tucson, Arizona. Results showed that Shading, Evaporative cooling, natural ventilation can be efficient cooling methods for this region, while mechanical cooling is only needed to maintain the required levels of comfort for $11 \%$ throughout the year (fig. 2).

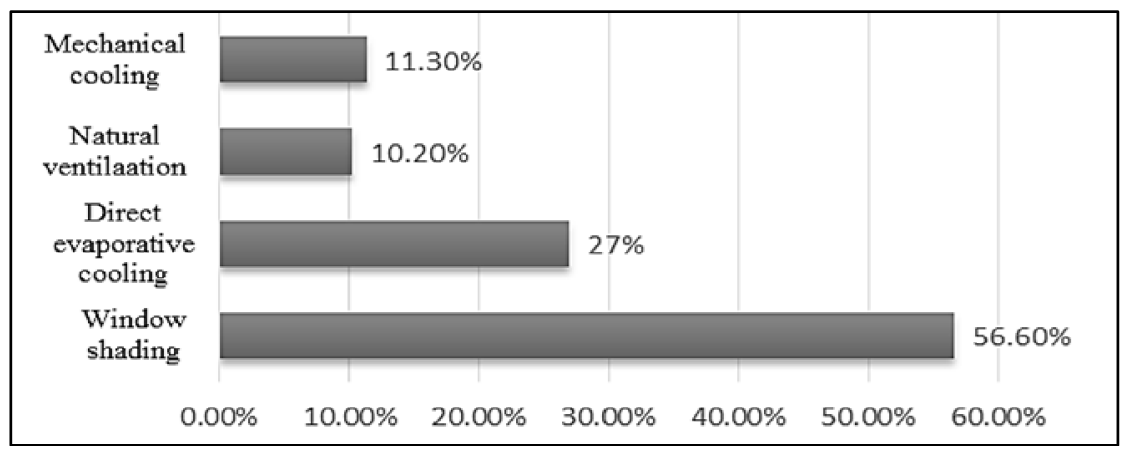

Figure 2: Annual efficiency percentage of cooling methods that can be used in Tucson, AZ to achieve required thermal comfort levels. 


\section{Theory to design}

In this research, the proposed building skin is meant to integrate shading, natural ventilation and evaporative cooling as passive cooling strategies to optimize the occupants' thermal comfort levels, and promoting the use of day light and views to increase the visual comfort for the space users (fig. 4).

The dynamic building skin is a cohesive part of adaptation and thermoregulation of the building that is responsible for collecting external climatic data and recording environmental changes, and then responding to these data regarding the orders received from the central processing unit

\subsection{Base case assumptions}

This research was conducted on a typical office space in Tucson, Arizona, which was used by the US Department of Energy as a benchmark for medium office buildings that meet ASHRAE Standard 90.1-2010 [4].

The study space is a south facing perimeter zone, with an area of 500 square feet. (20' wide * 25' deep), and with a floor to ceiling height of 9' and $33 \%$ window to wall ratio (fig 4). The proposed cooling system was a packaged single zone HVAC system, as office buildings in Tucson are typically cooled by mechanical systems with no opportunities to use natural ventilation.

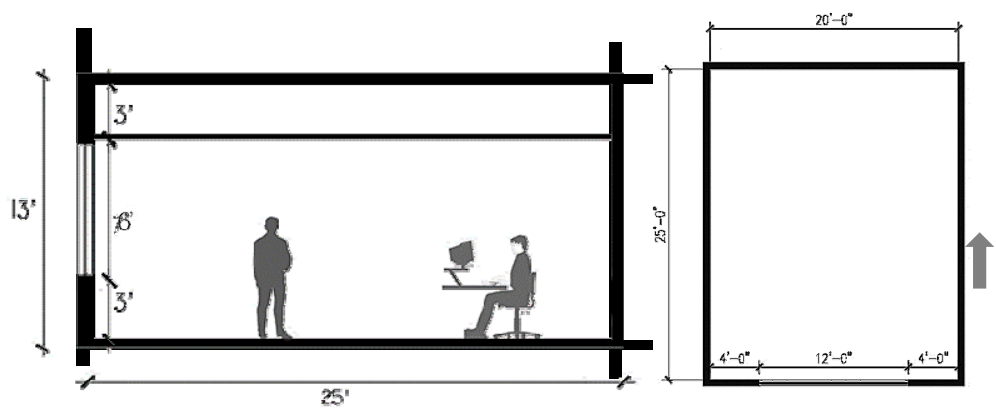

Figure 3: Section through the study space showing window location (left). The base case is a rectangular perimeter zone (right).

\subsection{Design}

The design proposes a double skin south-facing façade that is fully shaded and incorporates automated openings on the external and internal skins to induce natural ventilation. The external skin is equipped with wetted pads to be used as evaporative cooling mediums. These pads are expected to cool the air before allowing it to enter the cavity space and flow into the office space (figs 4 and 5).

The system was designed with three operating modes; natural ventilation mode, evaporative cooling mode and mechanical cooling mode. The central processing unit determines which mode to be used according the climatic data collected by the sensors inside the space and on the external skin. 


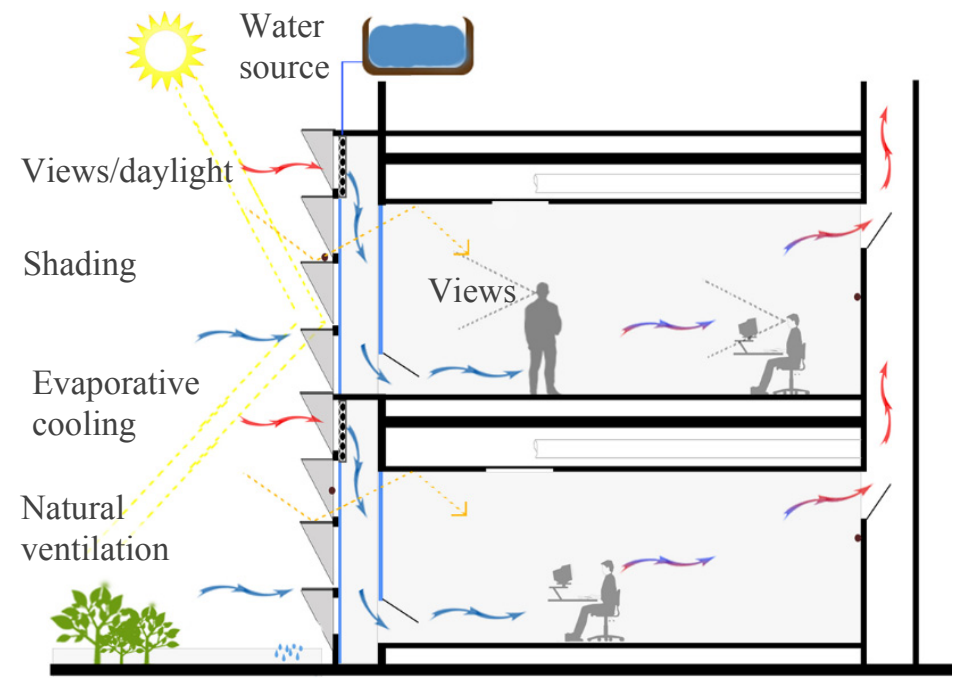

Figure 4: The proposed skin which integrates passive cooling strategies while optimizing the occupants' thermal and visual comfort.

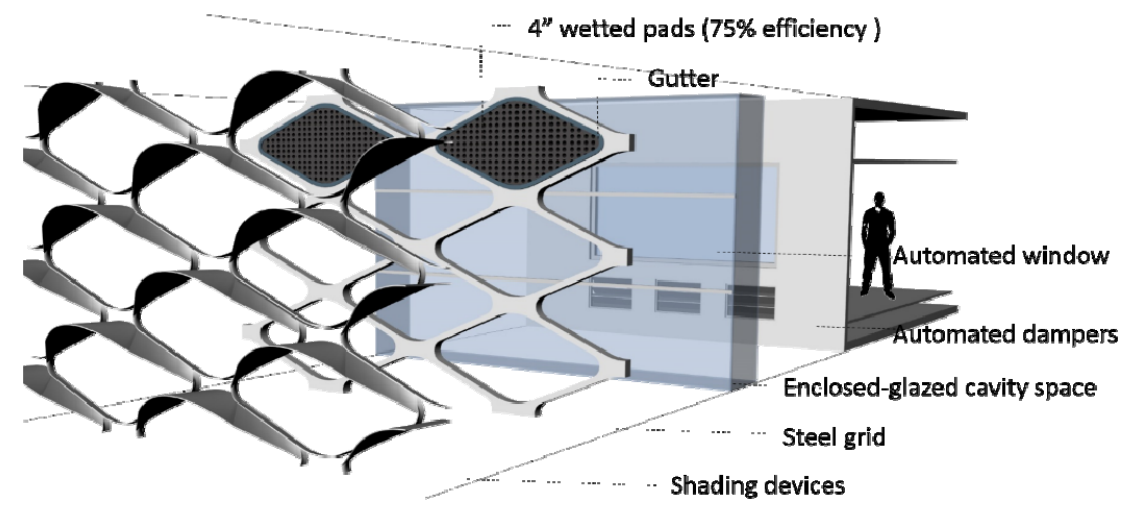

Figure 5: A 3D image that shows the layers of the façade system.

\subsubsection{Natural ventilation}

Ventilation is achieved by incorporating three $2 * 3$ ' openings in the lower part of the existing internal skin. These automated openings open and close based on the system operating mode (fig. 7B).

\subsubsection{Double skin façade (DSF)}

A layer of glass was added 3' away from the existing envelope to create a double skin façade that will enclose the cavity space (fig. 7C). The cavity space will be 
the connective and the transitive space between the outdoor air and the internal space. This layer also has an automated opening (as shown in fig. 5), which will allow natural ventilation into the space.

\subsubsection{Grid structure}

With the glazed layer added to the envelope, both cavity and interior spaces are susceptible to over-heating which requires efficient shading. A structural grid was added to support the external skin and hold the shading devices (fig. 7D).

A diagonal grid uses $20 \%$ less material than a regular grid; it also creates a more dynamic structure that will allow more views and daylight into the space.

\subsubsection{Shading devices}

Shading devices were designed to block the direct solar gain from March $21^{\text {st }}$ to September $21^{\text {st }}$, and allow the sun to penetrate through the envelope to passively heat the space in the winter (figs 6 and 7E). These devices were sized depending on the height of the area that they shade, which allows indirect light into the space.
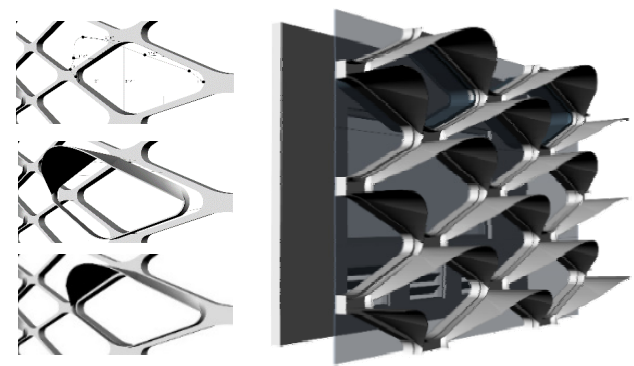

Figure 6: Sizing shading devices depended on shading the required areas while allowing daylight to penetrate through the space.

\subsubsection{Evaporative cooling}

Wetted evaporative cooling pads with $75 \%$ efficiency and 4" thickness were added to the upper part of the system (fig. 7F). These pads are supplied with water by a small electric pump. Placing the wetted pads on the upper part creates a down-draft cooling shaft that delivers cooled air to the internal space through the internal skin automated openings.

\section{Operating modes}

The previous design process depended on a thorough climatic analysis to determine the most effective design strategies and appropriate times to use each of these strategies to achieve the required level of thermal comfort. This analysis helped the authors prepare an operating schedule defining which cooling methods can be more efficient throughout the year (fig. 8). 
A

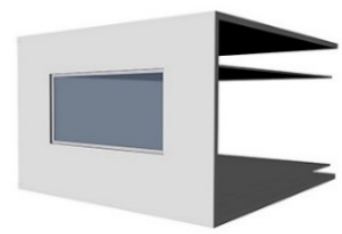

$\mathrm{B}$

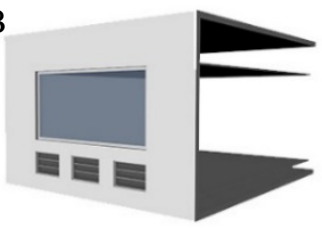

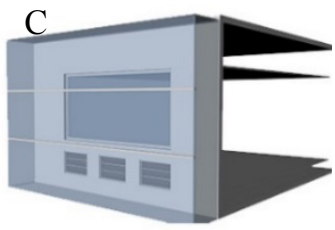

$\mathrm{D}$
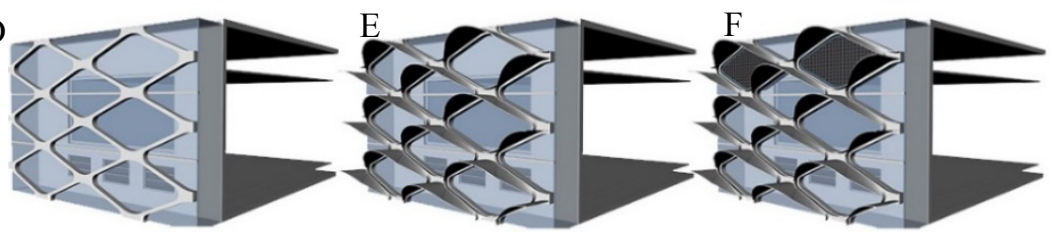

Figure 7: The design development of the system starting with the base case (A), and ending with the full system (D).

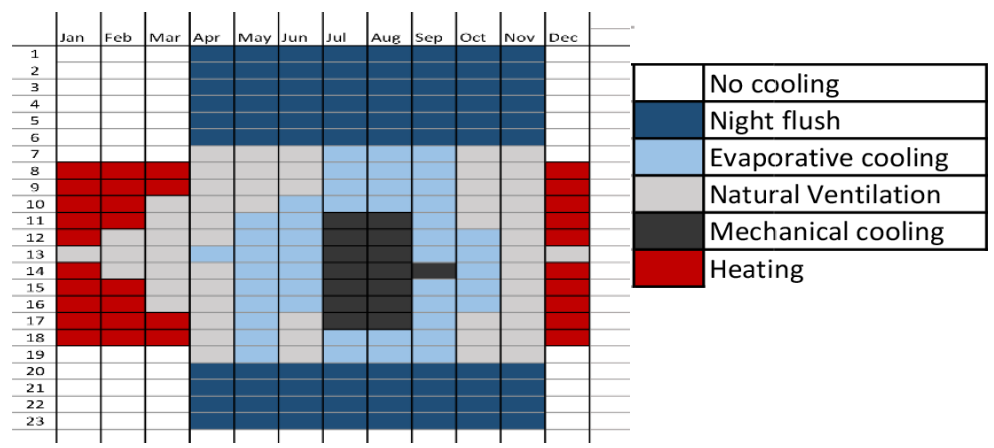

Figure 8:

System operating schedule.

\section{Methods}

In order to assess the performance of the proposed façade, multiple computer simulations were conducted on the design configurations in terms of achieving thermal and visual comfort standards and energy consumption. Diva for Rhino was used to help determine shading efficiency and illuminance levels in the space, Autodesk simulation CFD was used to test the performance of the three proposed operating modes, and COMFEN was used to evaluate energy consumption.

\subsection{Daylight simulation}

Shading and daylight simulations were done on both the base case and the proposed prototype to determine the change in performance (fig. 9). 

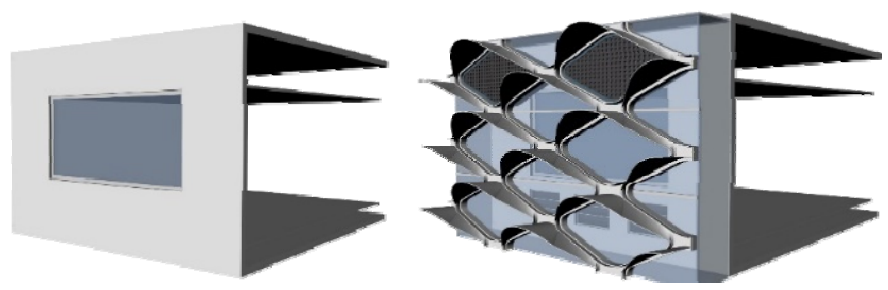

Figure 9: Simulation cases; before applying the proposed system (left) and after applying the system (right).

\subsubsection{Shading analysis}

The unshaded window in base case caused significant solar gain throughout the year. This results in overheating the space and increasing cooling loads (fig. 10).

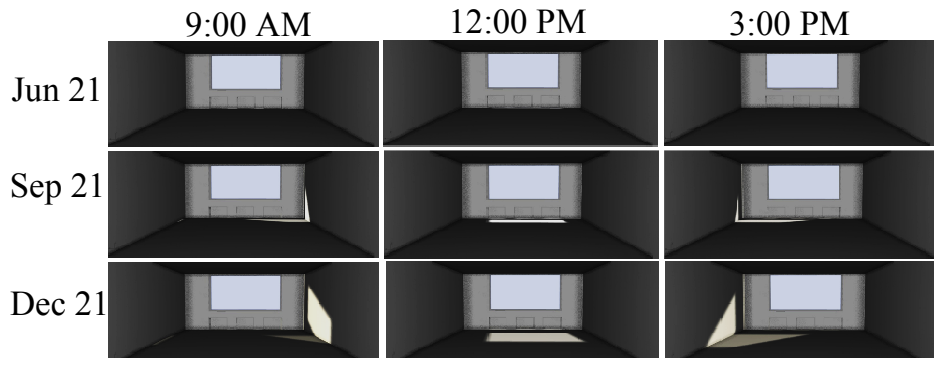

Figure 10: $\quad$ Base case shading analysis for different months and times.

The proposed façade system helped fully shade the space from March $21^{\text {st }}$ September $21^{\text {st }}$ and allowed direct solar gain during the winter for passive heating (fig. 11).

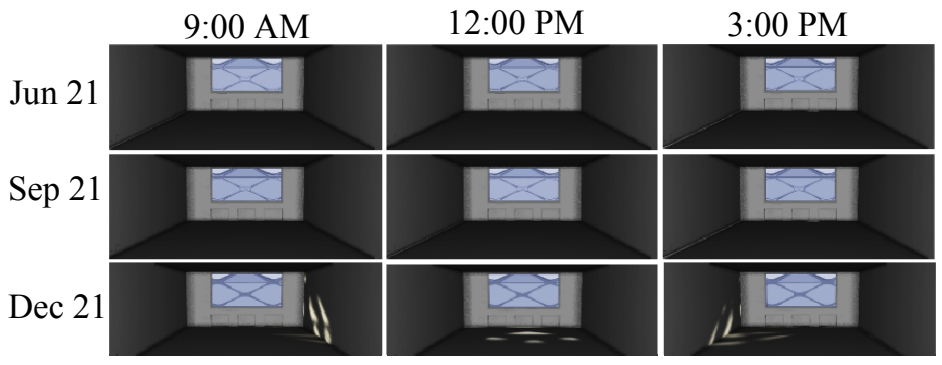

Figure 11: $\quad$ Proposed façade shading analysis showing effective shading. 


\subsubsection{Illuminance}

Illuminance, or light levels, is the total luminous flux incident on a surface per unit area [5]. Recommended illuminance for office spaces in general is 50 footcandles (ftcd). This number drops to $35 \mathrm{ftcd}$ for computer based office spaces [6].

The base case illuminance test showed very high light levels on the work plane near the window, these levels tremendously drop moving deeper into the space (fig. 12A). High illuminance indicates high heat gain, and the big difference in light levels results in visual discomfort for the users.

Efficient shading, introduced by the proposed façade, helped reduce the illuminance inside the space and significantly lower the differences in light levels across the space (fig. 12B). Therefore, decreasing the heat gain as well as optimizing the occupant's visual comfort.

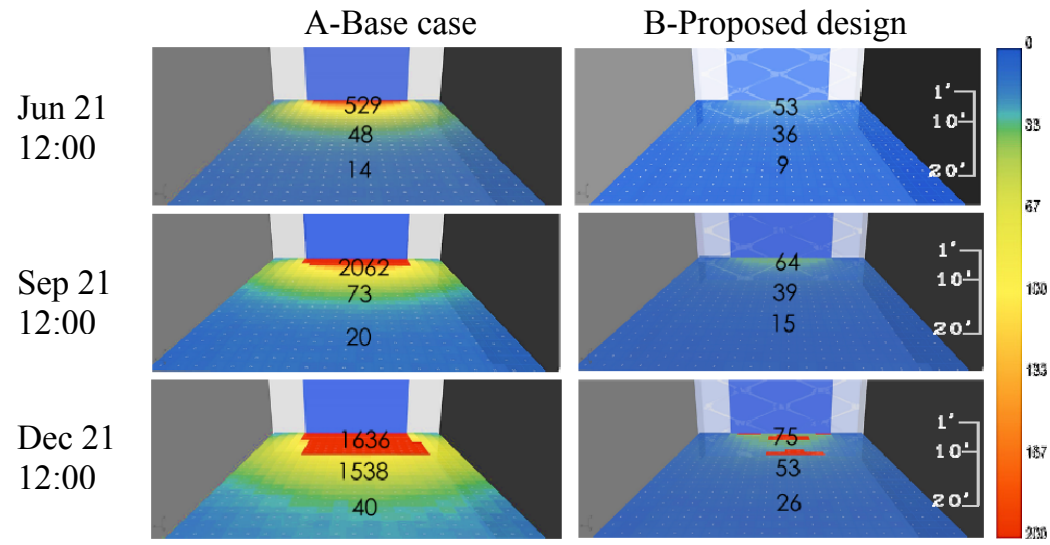

Figure 12: $\quad$ Illuminance in ftcd at 1', 10' and 20' from the south window.

\subsection{Computational fluid dynamics (CFD) simulation}

To evaluate the performance of the façade in terms of the efficiency of using natural ventilation and evaporative cooling. Each of the operating modes was tested (fig. 13). The results were validated and checked for compliance with ASHRAE 55-2004 standards for indoor thermal comfort standards.

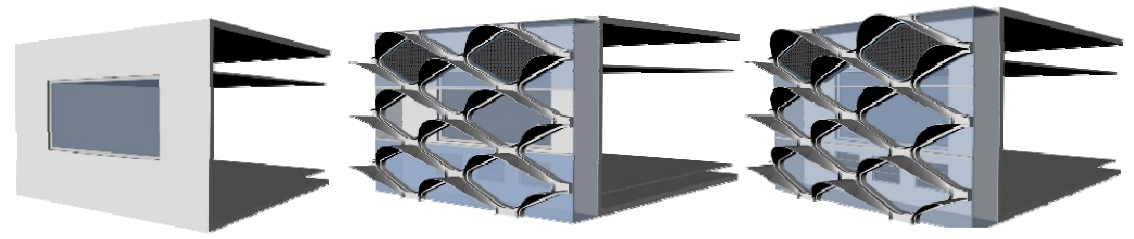

Figure 13: The three operating modes, (left to right) mechanical cooling mode, natural ventilation mode, evaporative cooling mode. 


\subsubsection{Base case/mechanical cooling}

The cooling system used for the base case is a single packaged zone system, with a supply temperature of 60 Fahrenheit, an air flow rate of $150 \mathrm{cfm}$ and a supply air velocity of $50 \mathrm{fpm}$. The space is occupied by 4 users.

Simulation results showed that mechanical cooling, expectedly, achieves indoor thermal comfort standards in terms of air velocity; as it is required that air velocity do not exceed 50 fpm (fig. 14).

Air temperature recommended by ASHRAE 55-2004 for indoor thermal comfort is $68 \mathrm{~F}-80 \mathrm{~F}$ during the summer. The simulation shows that the mechanical system also achieves the required range of temperature across the space (fig. 15).

Mechanical cooling mode simulations were conducted in order to be compared with the passive cooling modes in terms of performance and energy efficiency.

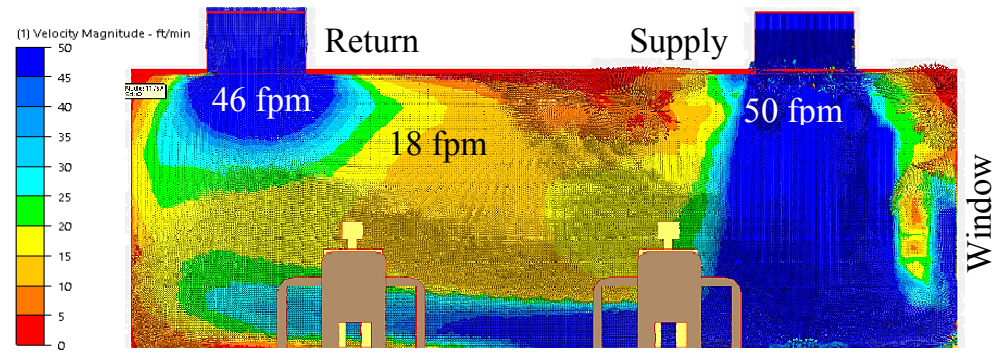

Figure 14: A cross section showing that air velocity complies with indoor thermal comfort standards.

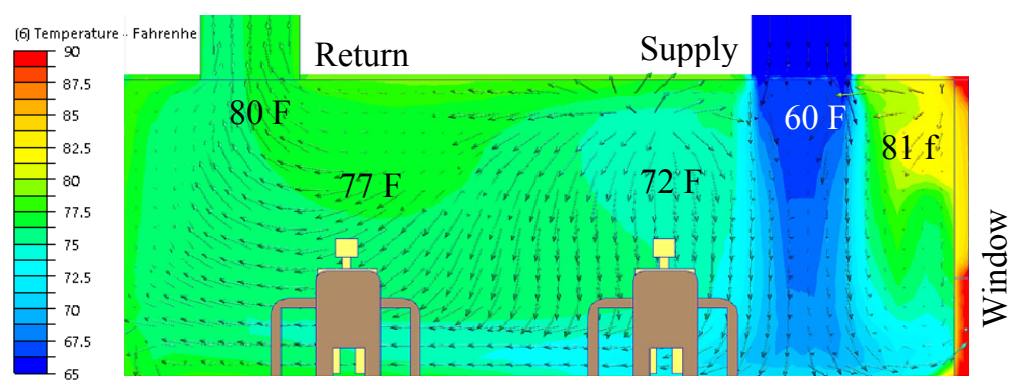

Figure 15: $\quad$ Air temperature across the test space is within required range.

\subsubsection{Natural ventilation mode}

Using natural ventilation to cool office spaces in hot arid regions can be limited due to high air velocity and air temperature. Air velocity in Tucson ranges between 1000-1500 fpm throughout the year, while naturally ventilated spaces require $40 \mathrm{fpm}-300 \mathrm{fpm}$ (ASHRAE 55-2004). The simulation was run on an 
April day, where outdoor air temperature was 78 F, 29\% relative humidity and air velocity was $1358 \mathrm{fpm}$. Results showed that as air penetrated through the external operable opening and hit the internal skin, the velocity dropped to almost $250 \mathrm{fpm}$. Then it decreased to almost $150 \mathrm{fpm}$ as it penetrated through the space (fig. 16).

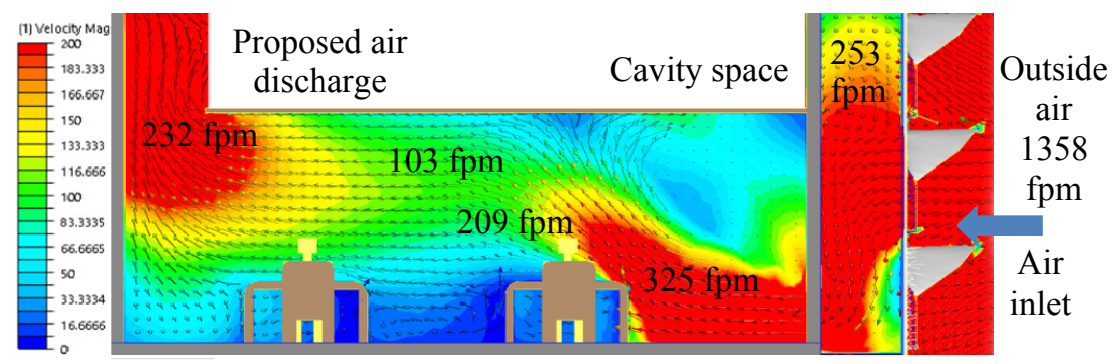

Figure 16: A cross section showing that air velocity, using the natural ventilation mode, complies with thermal comfort standards.

A slight change on air temperature was noticed, an increase by one degree, due to the heat generated by occupants and machines inside the space.

\subsubsection{Evaporative cooling mode}

This test was run on a June day; Air dry bulb temperature was 95 F, 69 F wet bulb temperature, $15 \%$ relative humidity, and $1215 \mathrm{fpm}$ air velocity. As the outdoor air went through the wetted pads, the temperature was reduced by evaporation and velocity was decreased. The cool air moved down the cavity space by gravity and entered the space through the internal automated openings (figs 17 and 18).

The air temperature was reduced from $95 \mathrm{~F}$ to $70 \mathrm{~F}$ by evaporation. This mode showed compliance with thermal comfort standards for office spaces (fig. 18).

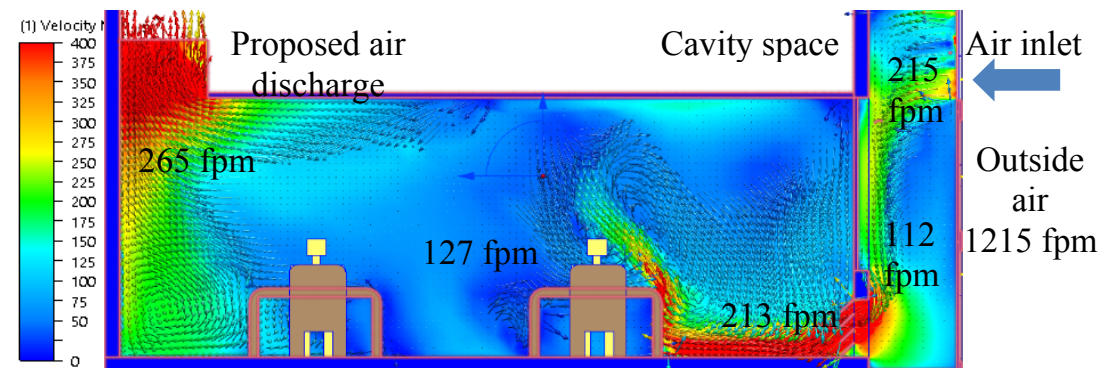

Figure 17: A diagram showing the façade performance in reducing outdoor air velocity to acceptable velocity ranges. 


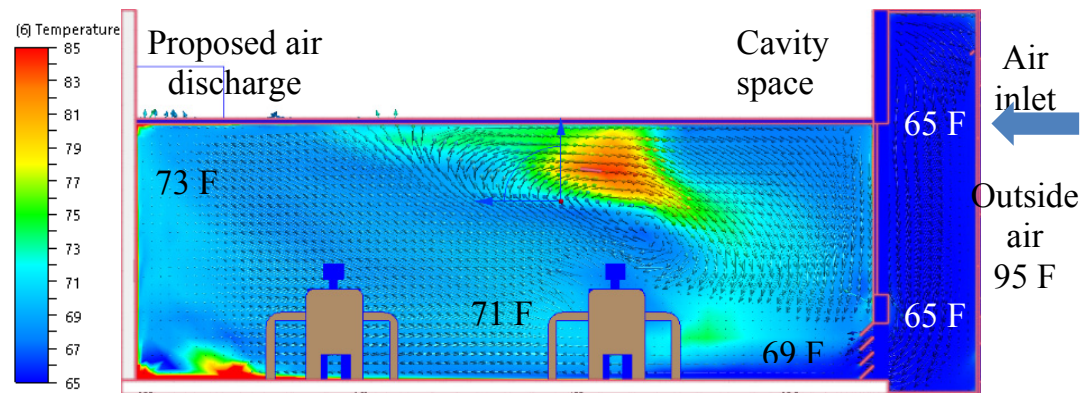

Figure 18: A section showing change in air temperature across the space.

\section{Results and conclusion}

Cooling load was significantly reduced by almost $70 \%$ throughout the year, while heating load was slightly increased for the winter months (figs 19 and 20).

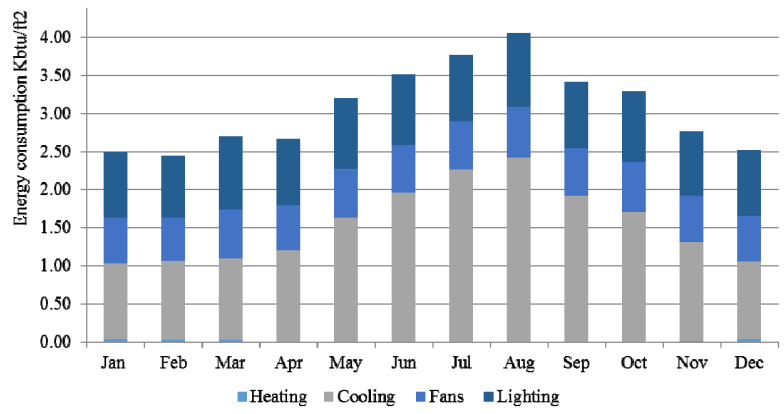

Figure 19: Base case: cooling load increased reaching a monthly energy consumption peak in August.

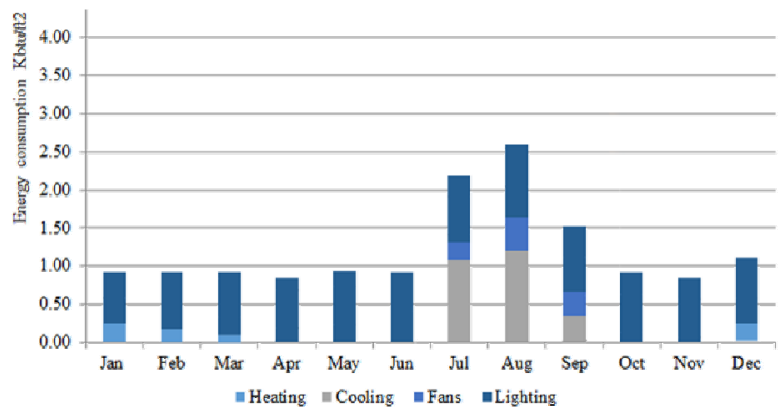

Figure 20: Proposed design: cooling load decreased dramatically while we noticed a slight increase in heating load. 
The proposed façade showed efficiency in performance using passive cooling strategies for office spaces in hot arid regions by reducing energy consumption while promoting thermal and visual comfort. This research can highly contribute in reducing energy consumption for commercial buildings, as well as providing a healthier work environment by using renewable sources of energy.

\section{References}

[1] Belal Khalid Abboushi, The effect of adaptive shading and the selective reflector light shelf on office building energy efficiency. pp. 16-20.

[2] Buildings Energy Databook, 2006. US Department of Energy and Annual Energy Review 2007. DOE/EIA-0384 (2007). Energy Information Administration, U.S. Department of Energy. June 2008.

[3] Proksch E, Brandner JM, Jensen JM. (2008).The skin: an indispensable barrier. Exp Dermatol. 17(12): 1063-72.

[4] US Department of energy/ Energy Efficiency \& Renewable Energy website, commercial prototype building models.

http://www.energycodes.gov/development/commercial/90.1_models

[5] Lechner, N. 2001. Heating, Cooling, Lighting design methods for architects. New York, John Wiley \& Sons Inc.

[6] Lighting, development, adoption and compliance guide. US Department of Energy, building technology program Sep 2012.

http://www.energycodes.gov/sites/default/files/documents/Lighting 